\title{
CFD Simulation Research on Agglomeration between Coal-fired Ash Fine Particulate and Atomized Droplets
}

\author{
Yiquan Guo $^{1 *}$, Junying Zhang ${ }^{2}$ \\ ${ }^{1}$ China Ship Development and Design Center, Wuhan, Hubei, 430064, P.R. China \\ ${ }^{2}$ School of Energy and Power Engineering, Huazhong University of Science and Technology, Wuhan, Hubei, 430074, P.R. China
}

\begin{abstract}
In this paper, a collision model between atomized droplets of agglomeration solution and particles is established. On this basis, the effects of flue gas temperature, atomized droplet diameter and other factors on the particle agglomeration process are studied. In addition, the evaporation model of agglomeration solution in the flue of a power plant is established for the coal-fired unit of power plant. Through CFD software, the variation of flow field velocity, temperature and pressure in the flue is simulated to determine whether the chemical agglomeration technology has negative impact on the actual operating conditions of the power plant. The simulation results show that the velocity and pressure of the flow field in the flue have no obvious change after the agglomerating agent is injected. Besides, the temperature drop of about $7{ }^{\circ} \mathrm{C}$. The droplets evaporate completely at a distance of 7-8 $\mathrm{m}$ after spraying. The evaporation time of droplets is within $1.6 \mathrm{~s}$
\end{abstract}

\section{Introduction}

Fine particulate matter (PM2.5) emitted from coal combustion can enter the lungs due to its small particle size, causing various respiratory diseases and even lung cancer[1]. Existing dust removal technologies, including electrostatic dust removal and bag dust removal technologies, have a removal efficiency of $99.9 \%$ for coarse particles, but a lower removal efficiency for fine particles. A large number of fine particles cannot be captured and removed by dust collectors due to their small sizes[2]. In view of this situation, chemical agglomeration technology[3] was adopted. A spray gun was installed in the flue in front of the dust collector to inject chemical agglomeration agent into the flue through compressed air and fully mixed with flue gas. Under the action of agglomeration solution, fine particles were agglomerated into particles with larger size, and then captured by dust removal equipment. Agglomeration phenomenon among particles has always been the focus of research in colloid science, materials science, physics and microbiology. Exploring the mechanism of particle collision agglomeration has always been the goal pursued by most scientific researchers. By clarifying the mechanism of particle agglomeration, we can better master the chemical agglomeration technology.

Bin et al.[4] using the universal density function theory (DFT) simulated the interaction process between agglomeration solution and orthosilicate crystal (TOS). The calculation results showed that the hydroxyl group in the water molecule and the oxygen atom of TOS molecule were connected together by hydrogen bonding. The acting energy was $-8.3 \mathrm{kal} \cdot \mathrm{mol}^{-1}$. The interaction process was shown in Fig. 1.

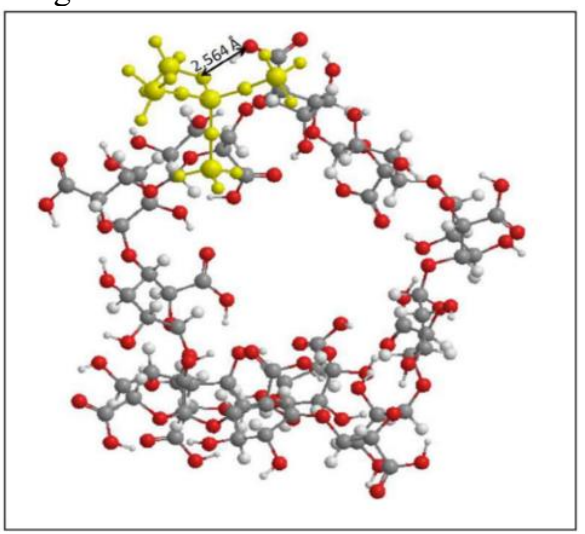

Figure 1. Simulation of combination of chemical agglomeration solution and TOS crystal

Based on the previous studies, Schaefer [5] and Goldszal [6] proposed two chemical agglomeration models, as shown in Fig. 2. When the chemical agglomeration solution was sprayed, the droplets absorbed fine particles and aggregated them together to form large particles. Due to the action of liquid bridge force, the free energy between particles increased and the droplets evaporated, then the particles form aggregates. Besides, the agglomeration solution connected fine particles together through macromolecular chain molecules with polar groups, thus forming aggregates. 


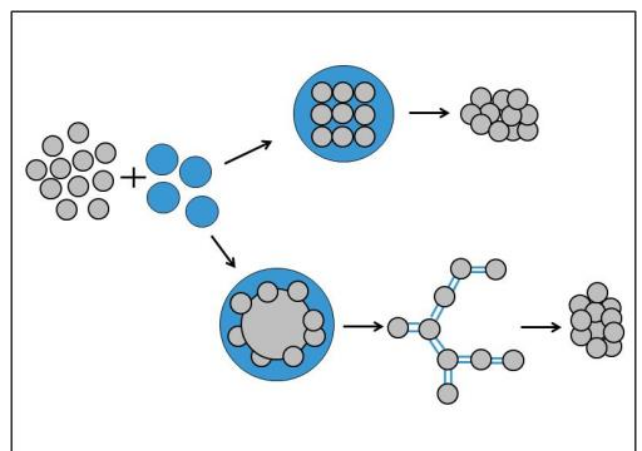

Figure 2. Chemical aggregation model of fly ash fine particulate

\section{Theoretical analysis of spray process of chemical agglomeration solutions}

\subsection{Collision model between atomized droplets of agglomeration solution and fine particles}

A collision model between spraying droplets and particles was established. The effects of various factors on the agglomeration effect of particles after the agglomeration solutions were sprayed were simulated $[7,8]$. The model assumed the following:

- The particle size was characterized by the average particle size of fine particles of coal-fired fly ash and atomized droplets of chemical agglomeration solution

- Assuming that the fly ash particles were agglomerated together after colliding and no longer separated. The shape of atomized droplets and particles before and after the agglomeration process were all regular spheres.

- Assuming that the fly ash particles had uniform distribution of particle mass and density. The total mass and volume of the system including atomized droplets and particles were conserved before and after agglomeration;

- Assuming that the particles were continuously dynamic during the air flow process. The movement of gas molecule was ignored.

\subsection{Numerical simulation of evaporation process of atomized droplets}

Atomized droplets of agglomeration solution will be affected by various forces in flue gas. The trajectory of liquid droplets could be calculated by establishing the equilibrium force equation of flue gas acting on the liquid droplets. According to the gas-solid two-phase flow theory, the forces acting on the moving droplets in the flow field included drag force, gravity, thermophoresis force, Brownian force and Saffman lift force, etc. Since the droplet size was small, other forces besided drag force and gravity force could be ignored. In Cartesian coordinate system, the force balance equation of the droplet in the $\mathrm{X}$-axis direction was $[9,10]$ :

$$
\frac{d v_{l}}{d t}=F_{D}\left(v_{\mathrm{g}}-v_{l}\right)+\frac{\mathrm{g}\left(\rho_{l}-\rho_{\mathrm{g}}\right)}{\rho_{l}}
$$

Among them, $\boldsymbol{F}_{\boldsymbol{D}}\left(\boldsymbol{v}_{\mathrm{g}}-\boldsymbol{v}_{\boldsymbol{l}}\right)$ was the drag force per unit mass on the particles. Besides,

$$
\begin{aligned}
& F_{D}=\frac{18 v_{\mathrm{g}}}{\rho_{l} d_{l}^{2}} \frac{C_{D} R e_{l}}{24} \\
& R e_{l}=\frac{\rho d_{l}\left|v_{l}-v_{\mathrm{g}}\right|}{\mu_{\mathrm{g}}}
\end{aligned}
$$

Here, $\boldsymbol{C}_{\boldsymbol{D}}$ was the drag coefficient. In discrete time steps, the above formula was integrated step by step to obtain the droplet velocity at each position on the particle track, thus obtaining the droplet track. Assuming that each item remained constant in every small actual interval, the droplet trajectory equation was abbreviated as:

$$
\frac{d v_{l}}{d t}=\frac{1}{\tau_{p}}\left(v_{\mathrm{g}}-v_{l}\right)
$$

Here, $\tau_{p}$ was the droplet relaxation time. When the liquid drops passed through the flue gas, the heat obtained from the flue gas was used to heat the liquid drops, and the heat balance equation of convection heat transfer was:

$$
m_{l} c_{l} \frac{d T_{l}}{d t}=h A_{l}\left(T_{\infty}-T_{l}\right)
$$

That was:

$$
\frac{d_{l} \rho_{l}}{6} c_{l} \frac{d T_{l}}{d t}=h\left(T_{\infty}-T_{l}\right)
$$

The convective heat transfer coefficient $\boldsymbol{h}$ between droplets and flue gas was given by the famous RanzMarshell relation

$$
N u=\frac{h d_{l}}{k_{\mathrm{g}}}=2.0+0.6 \operatorname{Re}_{l}^{1 / 2} \operatorname{Pr}^{1 / 3}
$$

The evaporation rate equation of droplet boiling was

$$
\frac{d d_{l}}{d t}=\frac{4 k_{\mathrm{g}}\left(1+0.23 R e_{l}^{1 / 2}\right)}{\rho_{l} c_{\mathrm{g}} d_{l}} \ln \left[1+\frac{c_{\mathrm{g}}\left(T_{\infty}-T_{l}\right)}{h_{f \mathrm{~g}}}\right]
$$

Table 1. Initial Parameters of Numerical Simulation of Chemical Agglomeration.

\begin{tabular}{ccc}
\hline Item & Unit & Value \\
\hline Smoke Temperature & $\mathrm{K}$ & 433 \\
Initial Velocity of Particles & $\mathrm{m} \cdot \mathrm{s}^{-1}$ & 20 \\
Smoke Density & $\mathrm{kg} \cdot \mathrm{m}^{-3}$ & 0.868 \\
Smoke Viscosity & $\mathrm{kg} \cdot \mathrm{m}^{-1} \cdot \mathrm{s}^{-1}$ & $22.7 \times 10^{-6}$ \\
Thermal Conductivity of Smoke & $\mathrm{W} \cdot \mathrm{m}^{-1} \cdot \mathrm{K}^{-1}$ & $3.53 \times 10^{-2}$ \\
Specific Heat Capacity of Smoke & $\mathrm{J} \cdot \mathrm{kg}^{-1} \cdot \mathrm{K}^{-1}$ & 1084 \\
Temperature of Agglomeration Solution Droplets & $\mathrm{K}$ & 323 \\
Initial Velocity of Agglomeration Solution Droplets & $\mathrm{m} \cdot \mathrm{s}^{-1}$ & 50 \\
Initial Diameter of Agglomeration Solution Droplets & $\mu \mathrm{m}$ & 25 \\
Density of Agglomeration Solution Droplets & $\mathrm{kg} \cdot \mathrm{m}^{-3}$ & 998.2
\end{tabular}




\begin{tabular}{ccc} 
Viscosity of Agglomeration Solution Droplets & $\mathrm{kg} \cdot \mathrm{m}^{-1} \cdot \mathrm{s}^{-1}$ & $1.003 \times 10^{-3}$ \\
Thermal Conductivity of Agglomeration Solution Droplets & $\mathrm{W} \cdot \mathrm{m}^{-1} \cdot \mathrm{K}^{-1}$ & 0.6 \\
Specific Heat Capacity of Agglomeration Solution Droplets & $\mathrm{J} \cdot \mathrm{kg}^{-1} \cdot \mathrm{K}^{-1}$ & 4200 \\
\hline
\end{tabular}
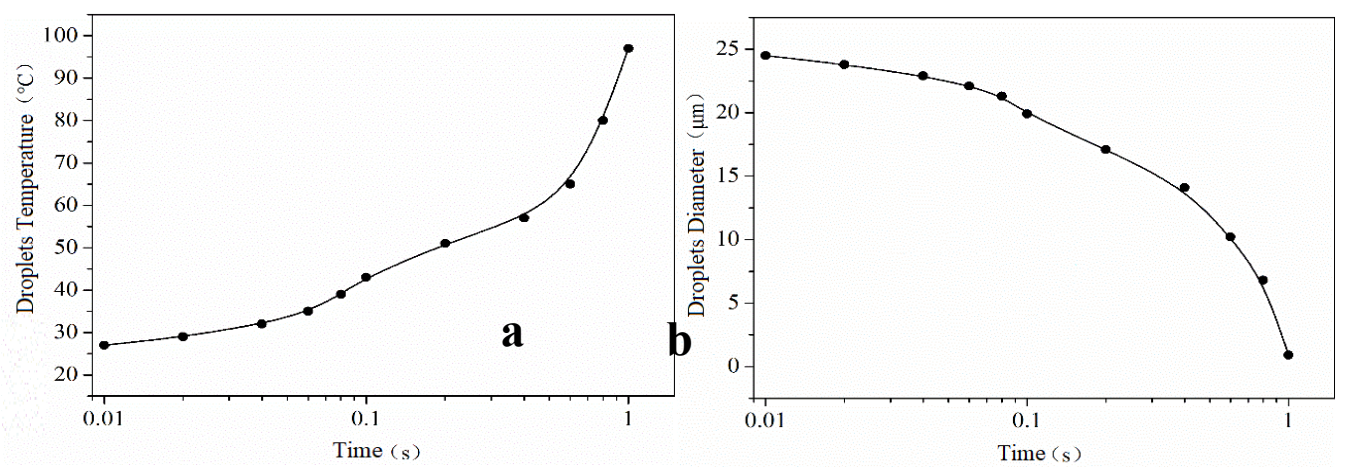

Figure 3. (a) Curve of droplet temperature versus time and (b) curve of droplet diameter versus time

As shown in Fig. 3, the evaporation time of liquid drops was about $1 \mathrm{~s}$.

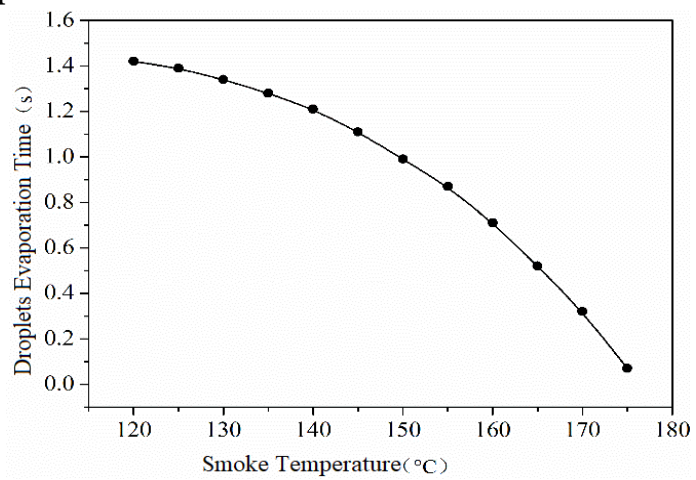

Figure 4. Variation curve of droplet evaporation time with flue gas temperature

As shown in Fig. 4, as the flue gas temperature increased, the evaporation time of droplets decreased significantly.

\section{CFD Simulation of flow field in flue of power plant}

\subsection{Mathematical model and initial conditions}

Three layers of spray guns were uniformly arranged in the vertical flue with the heights of $10 \mathrm{~m}, 12.5 \mathrm{~m}$ and $15 \mathrm{~m}$ respectively. Six spray guns were arranged on each floor. The horizontal spacing of each spray gun was $0.9 \mathrm{~m}$, and the spray guns were $1.75 \mathrm{~m}$ away from the wall. Each spray gun had 2 nozzles with a horizontal spacing of 0.8 $\mathrm{m}$. Agglomeration solution atomized into droplets with a particle size of 20-30 $\mu \mathrm{m}$ under the action of compressed air $(0.3 \mathrm{MPa})$. The specific location of spray gun arrangement was shown in Fig. 5.

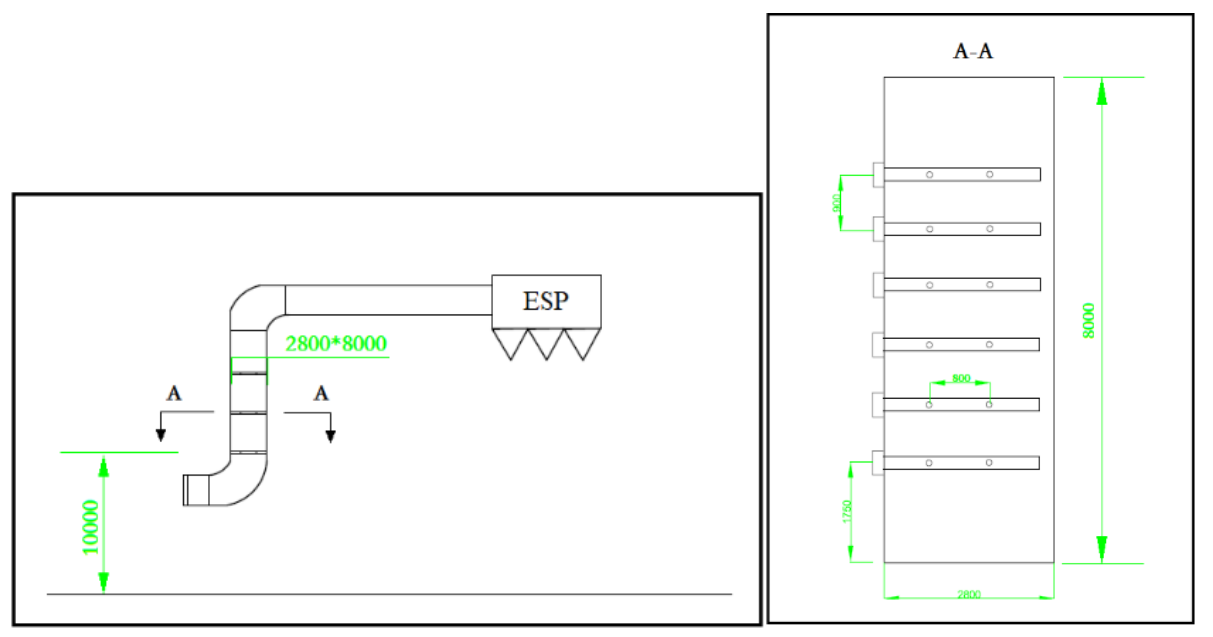

Figure 5. Arrangement position schematic diagram of spray guns and nozzles

Here, we used CFD software Fluent to simulate the flow field in the flue of the power plant. The variation of velocity, temperature and pressure of flow field in flue after chemical agglomeration solution was sprayed into flue was studied to determine whether chemical agglomeration technology had negative impact on actual operating conditions of power plant. The model and grid division were shown in Fig. 6. 


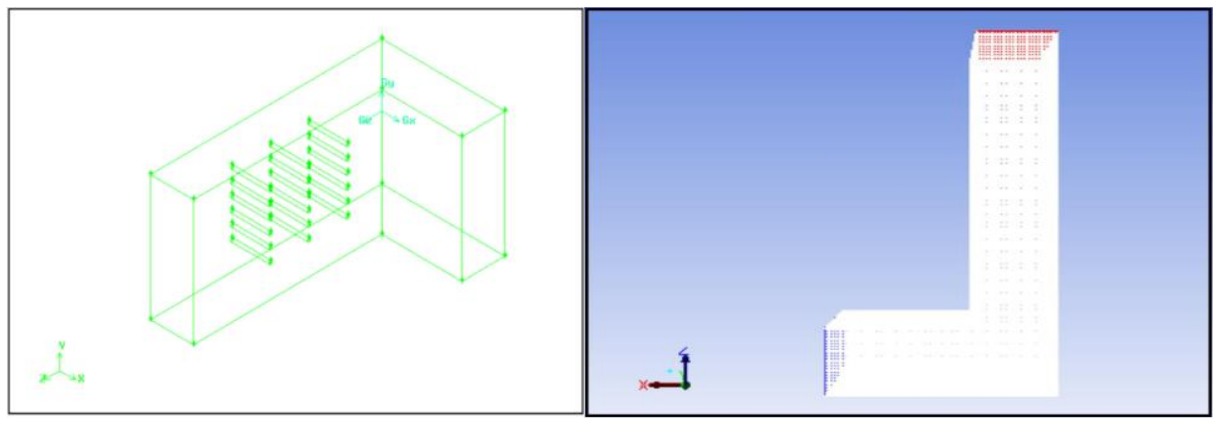

Figure 6. Modeling and grid division of power plant flue

Simulation parameters: flue gas temperature was 130 ${ }^{\circ} \mathrm{C}$, flue gas flow rate was $12 \mathrm{~m} \cdot \mathrm{s}^{-1}$, injection quantity of chemical agglomeration solution was $3 \mathrm{t} \cdot \mathrm{h}^{-1}$, temperature was $27^{\circ} \mathrm{C}$, injection pressure was $0.3 \mathrm{Mpa}$. The number of nozzle injection sources in the liquid phase was set at 36 , and their arrangement positions were the same as those previously designed. The diameter of droplet was $25 \mu \mathrm{m}$. Flow rate of single ejector source was $0.0235 \mathrm{~kg} \cdot \mathrm{s}^{-1}$, and atomization angle was $22^{\circ}$, and injection velocity was 5 $\mathrm{m} \cdot \mathrm{s}^{-1}$. The injection direction was opposite to the flue gas flow direction. In the process of atomization, droplets would not only collide but also burst. In order to reflect the evaporation effect more truly, a spray burst Wave model was added to the dispersion term.

\subsection{Simulation results analysis}

Using DPM Model in CFD Software Fluent, the gas-liquid two-phase coupling calculation was carried out after adding atomized droplet parameters to the initial calculation and the results were obtained.

(1) Velocity cloud map

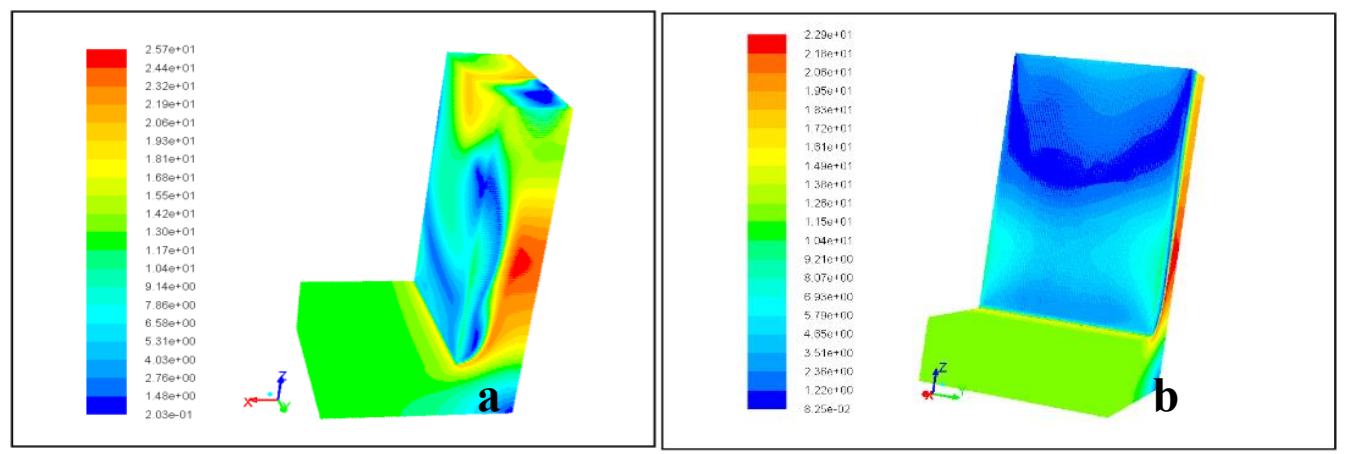

Figure 7. Cloud map of velocity distribution in Flue of coal-fired power plant

As shown in Fig. 7a, the flow field in the flue and the distribution of flue gas velocity in its longitudinal section were in the pure flue gas state. It can be seen that the speed of flue gas remained unchanged at $12 \mathrm{~m} \cdot \mathrm{s}^{-1}$. In the vertical flue, due to the existence of corners, the flue became narrower, the cross-sectional area decreased, and the flue gas velocity gradually increased to $8 \mathrm{~m} \cdot \mathrm{s}^{-1}$. The simulation results of flue gas flow rate after spraying the solution were shown in Fig. 7b. As the speed of atomized liquid drops was only $5 \mathrm{~m} \cdot \mathrm{s}^{-1}$, which was far less than the flow rate of flue gas, and the amount of water injected by a single nozzle was $0.0235 \mathrm{~kg} \cdot \mathrm{s}^{-1}$, which was very small relative to the amount of flue gas. Therefore, its influence on the flow rate of flue gas in the whole flue was very small.

(2) Temperature cloud map

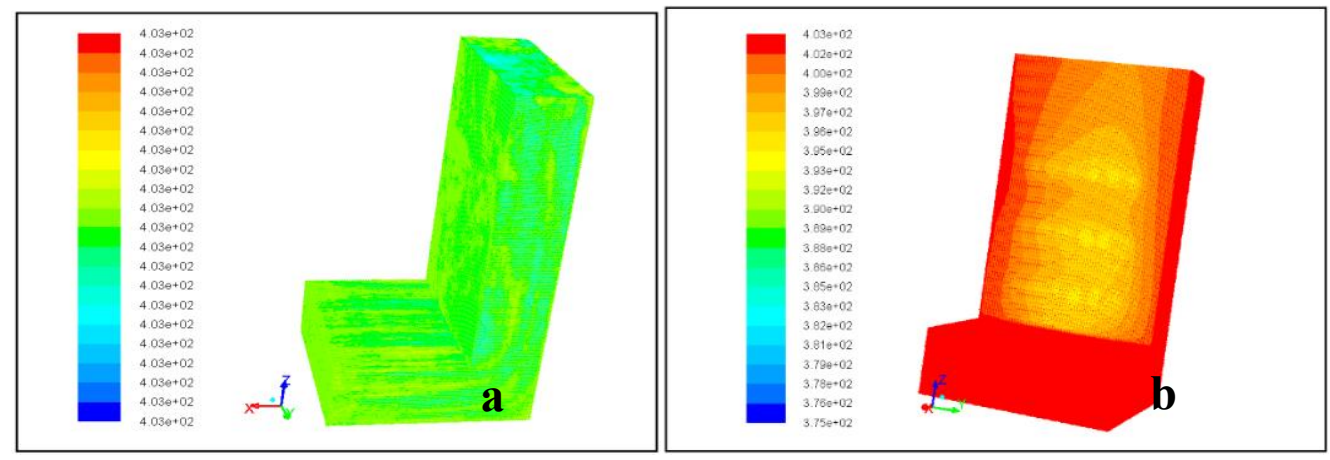

Figure 8. Cloud map of temperature distribution in Flue of coal-fired power plant 
Before spraying the chemical agglomeration drops, due to the heat preservation measures in the flue, there was no heat loss in the local flue, and the temperature of the whole flue was basically maintained at $130{ }^{\circ} \mathrm{C}$ as shown in Fig. 8a. After spraying the agglomeration solution, the droplets had completely evaporated, and the stabilized flue gas temperature was $123{ }^{\circ} \mathrm{C}$. Compared with that without spraying the solution, the temperature drop caused by solution evaporation was about $7{ }^{\circ} \mathrm{C}$. By observing the temperature distribution, it could be concluded that the atomized droplets completely evaporated within 7-8 $\mathrm{m}$ after ejection, and the evaporation time was within $1.6 \mathrm{~s}$ according to the velocity of atomized droplets of agglomerating agent 5 $\mathrm{m} \cdot \mathrm{s}^{-1}$. Therefore, the injected solution had no influence on ESP and subsequent equipment.

(3) Pressure cloud map

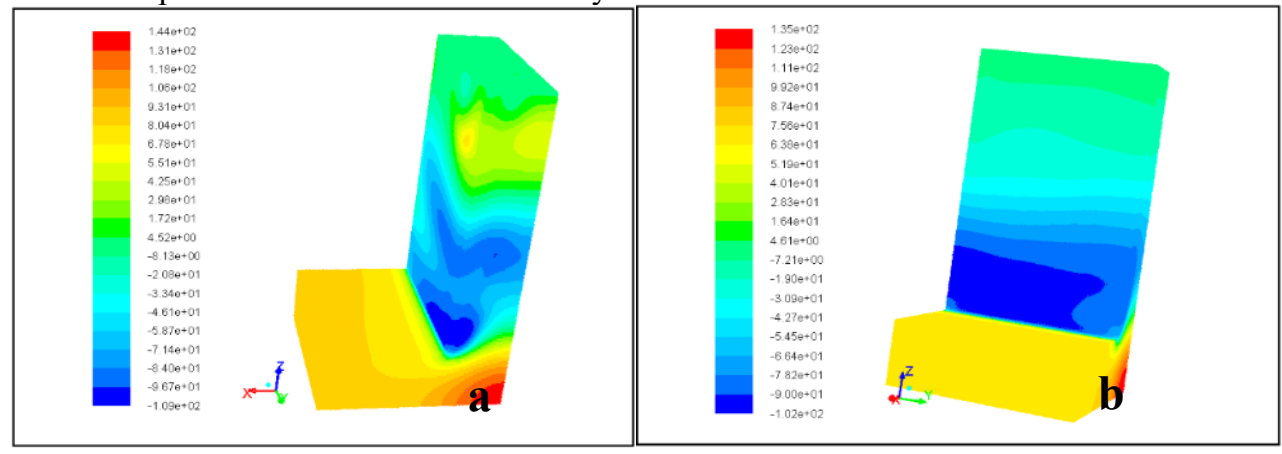

Figure 9. Cloud map of pressure distribution in Flue of coal-fired power plant

The flow field and flue gas pressure distribution in the flue were shown in Fig. 9a. The flue gas pressure was related to the flue gas flow rate. Where the flue gas velocity was stable, the flue gas pressure also had no obvious change, so the flue gas pressure in the horizontal flue section basically remained unchanged, and the pressure in the front wall surface of the flue in the vertical flue section was small due to the low flue gas velocity. After injecting chemical agglomeration solution, the pressure of flow field in flue had no obvious change.

In general, after injecting the chemical agglomeration solution into the flue of the power plant, the flue gas velocity and pressure in the flow field had no obvious change except that the flue gas temperature was reduced by $7{ }^{\circ} \mathrm{C}$ compared with that without the agglomeration solution. Therefore, chemical agglomeration would not adversely affect the normal operation of the power plant.

\section{Conclusions}

In this paper, the interaction process between atomized droplets and particles after spraying chemical agglomeration solution was numerically simulated, and the effects of flue gas temperature, atomized droplet diameter and other factors on solution evaporation process were studied. On this basis, the evaporation model of agglomeration solution in power plant flue was established. The simulation results show that after the agglomeration solution was injected, the velocity and pressure of the flow field in the flue had no obvious change. Besides, the smoke temperature dropped of about $7{ }^{\circ} \mathrm{C}$. Observing the temperature distribution, it can be concluded that the spray evaporated completely at a distance of 7-8 $\mathrm{m}$ after spraying, and the evaporation time was within $1.6 \mathrm{~s}$. Therefore, spraying agglomeration solution had no influence on the ESP and subsequent equipment.

\section{References}

1. Pui D Y H, Chen S C, Zuo Z. PM 2.5 in China: Measurements, sources, visibility and health effects, and mitigation[J]. Particuology, 2014, 13: 1-26.

2. Xiong Guilong, Li Shuiqing, et al. Development of advanced electrostatic precipitation technologies for reducing PM2.5 emissions from coal-fired power plants. [J]Proceedings of the CSEE,2015,35(9):22172223

3. Guo YQ, Zhang JY, Zhao YC, Wang SL, Jiang C, Zheng CG. Chemical agglomeration of fine particles in coal combustion flue gas: Experimental evaluation. Fuel, 2017, 203: 557-569.

4. Bin H, Yang Y, Lei Z, et al. Experimental and DFT studies of PM 2.5 removal by chemical agglomeration. Fuel, 2018, 212: 27-33.

5. Schæfer T, Mathiesen C. Melt pelletization in a high shear mixer. IX. Effects of binder particle size. International journal of pharmaceutics, 1996, 139(12): 139-148.

6. Goldszal A, Bousquet J. Wet agglomeration of powders: from physics toward process optimization. Powder Technology, 2001, 117(3): 221-231.

7. Lian G, Thornton C, Adams M J. Discrete particle simulation of agglomerate impact coalescence. Chemical Engineering Science, 1998, 53(19): 3381 3391.

8. Hetsroni G. Handbook of multiphase systems. 1982.

9. Ranz W E, Marshall W R. Evaporation from drops. Chem. Eng. Prog, 1952, 48(3): 141-146.

10. Jakubczyk D, Kolwas M, Derkachov G, et al. Evaporation of micro-droplets: the" radius-squarelaw" revisited. Acta Physica Polonica-Series A General Physics, 2012, 122(4): 709. 